\title{
Robust and General Procedure for Carbon Isotope Labeling of Linear Urea Derivatives with Carbon Dioxide
}

\author{
Victor Babin, ${ }^{[a]}$ Antoine Sallustrau, ${ }^{[a]}$ Olivier Loreau, ${ }^{[a]}$ Fabien Caillé,${ }^{[b]}$ Amélie Goudet, ${ }^{[a]}$ Héloïse \\ Cahuzac, ${ }^{[\mathrm{c}]}$ Antonio Del Vecchio, ${ }^{\left[{ }^{[a]}\right.}$ Frédéric Taran, ${ }^{[\mathrm{a}]}$ Davide Audisio ${ }^{[\mathrm{a}] *}$
}

[a] Université Paris Saclay, CEA, Service de Chimie Bio-organique et Marquage, DMTS, F-91191, Gif-sur-Yvette, France.

[b] UMR 1023 IMIV, Service Hospitalier Frédéric Joliot, CEA, Inserm, Université Paris Sud, CNRS, Université Paris-Saclay, Orsay, France

[c] Université Paris-Saclay, Département Médicaments et Technologies pour la Santé (DMTS), CEA, INRAE, SIMoS, 91191 Gif-sur-Yvette, France

\begin{abstract}
Carbon isotope labeling is a traceless technology, which allows tracking the fate of organic compounds either in the environment or in living organisms. Despite recent advances in the field, the development of robust and general technologies remains a significant task. This full article reports on a general approach to label urea derivatives with all carbon isotopes, including ${ }^{14} \mathrm{C}$ and ${ }^{11} \mathrm{C}$. Based on a Staudinger aza-Wittig sequence, it provides access to all aliphatic/aromatic urea combinations as well as to semicarbazides, sulfonylureas, hydroxyl ureas, and simple terminal ureas. A de-risking approach was developed to evaluate the robustness of the reaction. This technology is based on $\left[{ }^{14} \mathrm{C}\right] \mathrm{CO}_{2}$ screening that allowed to investigate the tolerance of the procedure with most representative heterocycles and functional groups found in FDA approved drugs.
\end{abstract}

\section{Introduction}

Radioisotope labeling is a fundamental topic in nuclear medicine, medicinal chemistry and has multiple implications in drug design and development. ${ }^{1}$ The peculiar physical proprieties of radionuclides allow the collection of precious data for ADMET studies (Absorption, Distribution, Metabolism, Excretion and Toxicological) with long life $B^{-}$isotopes ${ }^{2}$ and the diagnosis of pathological disease with non-invasive Positron Emission Tomography (PET) imaging for short life $b^{+}$isotopes. ${ }^{3}$ In this context, carbon plays a privileged role: ubiquitously present in organic compounds, it is an ideal element for isotopic labeling of pharmaceuticals. Two radioisotopes of carbon are pharmaceutically relevant: carbon-11 $\left({ }^{11} \mathrm{C}\right) \mathrm{a}$ positon $\left(B^{+}\right)$emitter with a remarkably short half-live $\left(t_{1 / 2}=20.4\right.$ minutes) and carbon-14 $\left({ }^{14} \mathrm{C}\right)$ a longlived electron $\left(B^{-}\right)$emitter ( $t t_{2}=5730$ years). ${ }^{4}$ To introduce a radioactive isotope onto a desired molecule the synthetic strategy should be compliant to specifications such as: short reaction time, high yield and generate minimal amounts of radioactive waste. In line with these recommendations, late-stage labeling appears as the most appropriate strategy. ${ }^{5}$ 


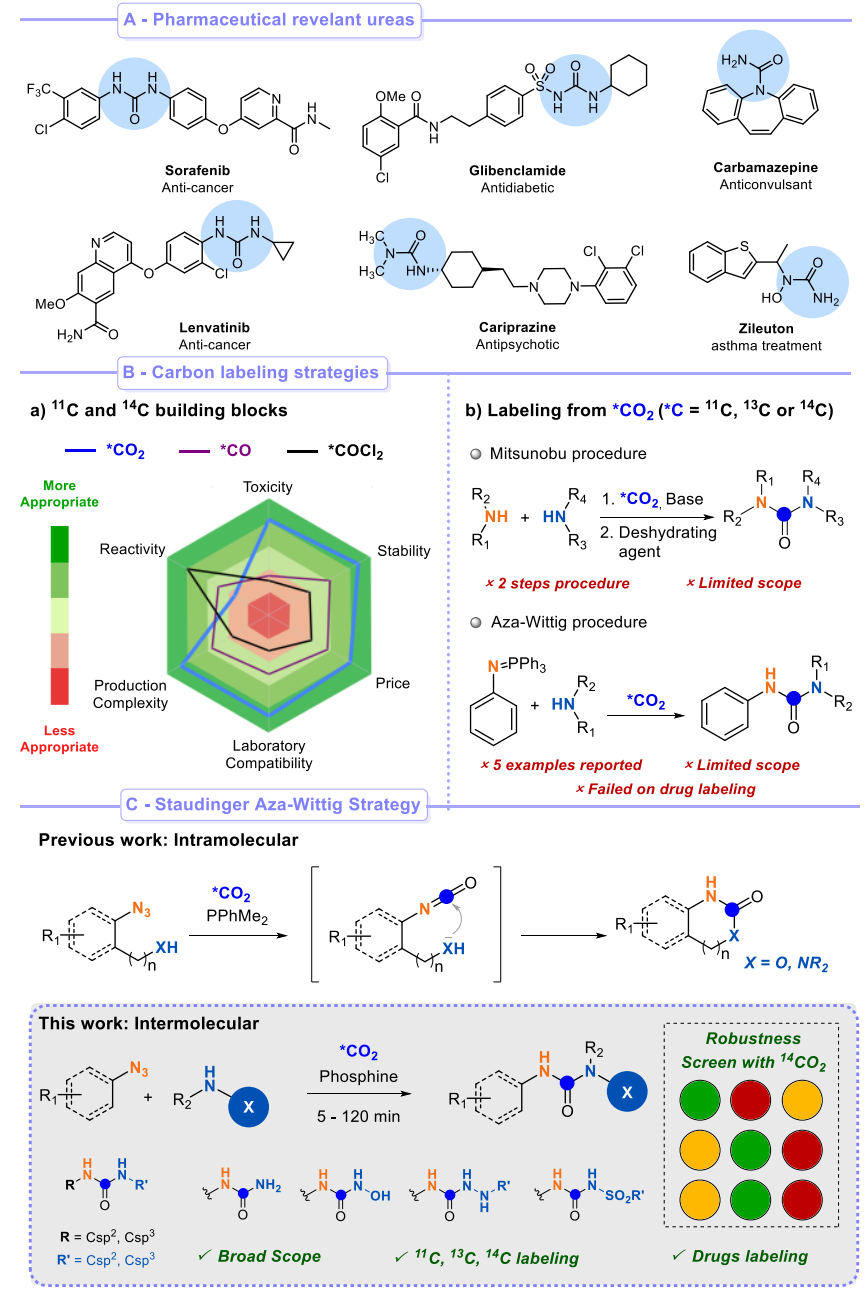

Scheme 1. A - Relevant examples of ureas substructures; B - a) Carbon isotope building blocks used for labeling; b) Synthetic strategies to access radiolabeled ureas; $C$ - Staudinger Aza-Wittig procedure.

The urea substructure is a fundamental building block in medicinal chemistry. It is found in numerous FDA approved drugs for a variety of human diseases and countless number of pharmaceutically relevant compounds (Scheme $1 \mathrm{~A}$ ). ${ }^{6}$ According to a recent study by Ertl et al., it is the $14^{\text {th }}$ most frequent functional group occurring in bioactive molecules described in medicinal chemistry literature. ${ }^{7}$ This functional group represents an attractive target for the labeling of drugs at the carbonyl group. Three main reagents are known for the radiocarbonylation of ureas (Scheme $1 \mathrm{~B}, \mathrm{a}) .{ }^{8}\left[{ }^{11 / 14} \mathrm{C}\right]$ Phosgene was frequently used due to its high reactivity, but its complex chemical production requiring hazardous reactants, such as $\mathrm{C}$-labeled $\mathrm{CO}$ and $\mathrm{Cl}_{2}$, and the need for specialized equipments drastically reduced its utilization. ${ }^{9,10}\left[{ }^{11 / 14} \mathrm{C}\right]$ Carbon monoxide is a building block suitable for installing the carbonyl group of ureas into organic compounds, through metal-catalyzed procedures or selenium mediated synthesis. ${ }^{11}$ Nevertheless, its utilization is not trivial due to the inherent toxicity and the timeconsuming production, which might require harsh conditions. ${ }^{12}$ In addition, $\left[{ }^{14} \mathrm{C}\right] \mathrm{CO}$ was described to undergo radiolysis and its limited stability prevents storage. ${ }^{13}\left[{ }^{11 / 14} \mathrm{C}\right]$ Carbon dioxide ${ }^{14}$ fulfills the handiest criteria as precursor: it is the primary radioactive carbon source from which derive all ${ }^{11} \mathrm{C}$ - and ${ }^{14} \mathrm{C}$-labeled compounds, has a remarkable stability to radiolysis and has a suitable safety profile compared to $\mathrm{CO}$ and $\mathrm{COCl}_{2}$. Two main procedures have been established for the labeling of linear ureas directly from $\left[{ }^{11 / 14}\right] \mathrm{CO}_{2}$. On one hand, a Mitsunobu approach using a base (BEMP or DBU) to trap $\mathrm{CO}_{2}$ and a dehydrating agent $\left(\mathrm{POCl}_{3}\right)$ to afford unsymmetrical ureas. ${ }^{15}$ This two-step procedure has been 
utilized both for ${ }^{11} \mathrm{C}$ and ${ }^{14} \mathrm{C}$ labeling, but it is limited by a moderate functional group compatibility. In 2006, van Tilburg published an Aza-Wittig approach starting from commercially available triphenylphosphine phenylimide and amines affording unsymmetrical ureas with moderate yields. ${ }^{16}$ To date, this methodology was applied only to four amine substrates. Importantly, it was unsuccessful on drug radiolabeling despite different attempts to modify and reverse the nature of the triphenylphosphinimine/amine partners. ${ }^{17}$ It is worth of note that all previous procedures are limited to ureas bearing carbon-substituents on positions 1 and 3 . Scaffolds broadly found in pharmaceuticals such as sulfonylureas, hydroxyl ureas, semicarbazides or simple terminal ureas still constitute a formidable challenge for radiolabeling. ${ }^{18}$

The current state of the art highlights the lack of a robust and general method to efficiently label unsymmetrical ureas and their derivatives. We recently reported an intramolecular Staudinger AzaWittig (SAW) approach to label cyclic ureas and carbamates from stoichiometric $\left[{ }^{11 / 14}\right] \mathrm{CO}_{2}$ (Scheme 1C).${ }^{19}$ The close proximity of the nucleophile to the azide was fundamental for a facile intramolecular attack onto the isocyanate generated in situ.
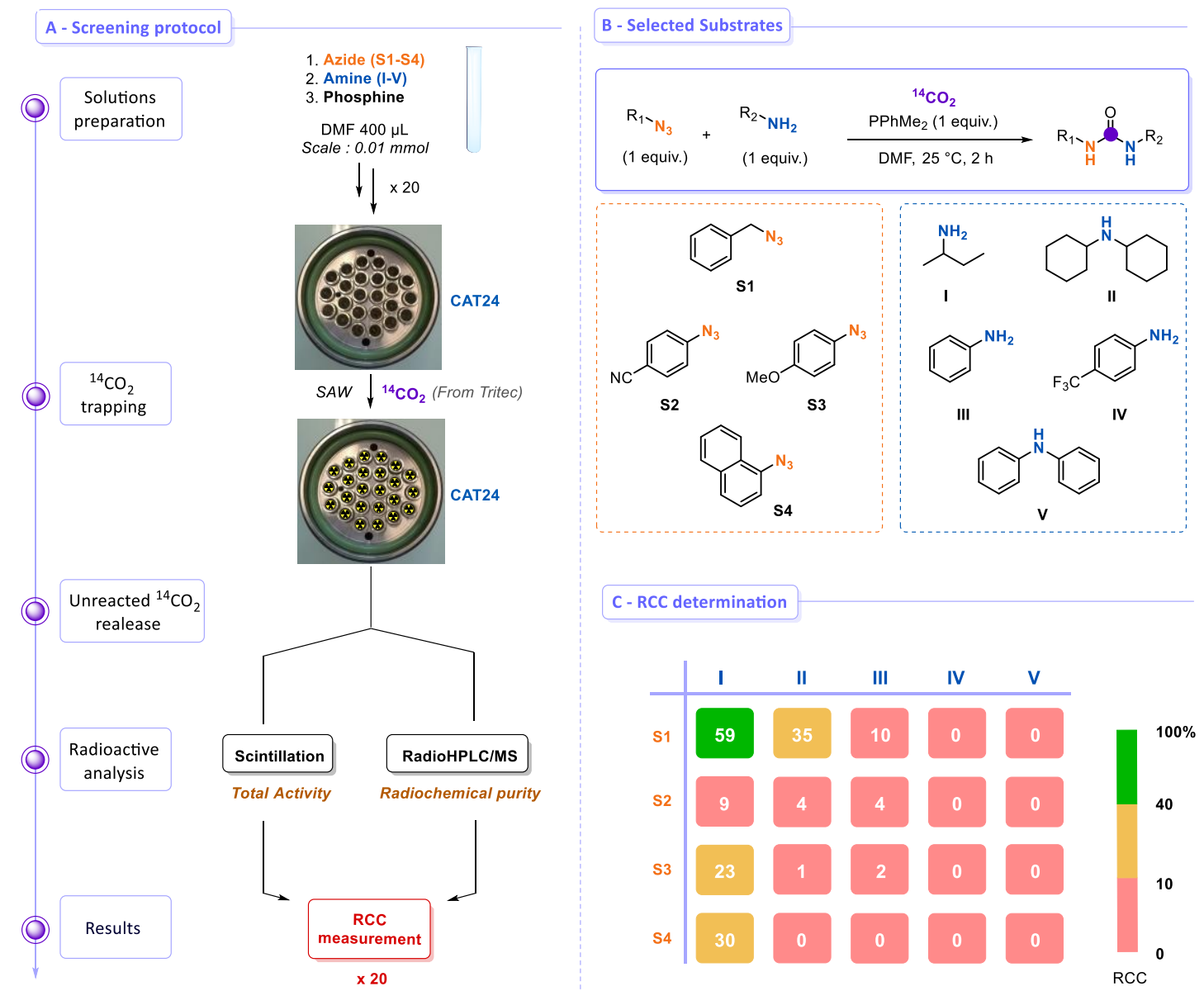

Scheme 2. ${ }^{14} \mathrm{CO}_{2} /$ Screen. A) Screening procedure based on the use of $\left[{ }^{14} \mathrm{C}\right] \mathrm{CO}_{2}$. For additional details please see the SI. B) Substrates selected for the screening. C) Results of the screening expressed as radiochemical conversion (RCC).

We now look to develop an intermolecular SAW procedure to offer a straightforward access to unsymmetrical carbon labeled ureas including hydroxyl ureas, terminal ureas, semicarbazides, $S$ thiocarbamates and sulfonylureas. At the outset, a number of challenges were anticipated, such as: (1) the parasite formation of symmetrical ureas, (2) difference in reactivity based on the electronic nature 
of both the azide and amine partners, (3) a lack of generality of the methodology and (4) an undesired reaction, such as amine carbonation, competing with the minute amounts of $\mathrm{CO}_{2}$ available. To anticipate and manage these issues, a de-risking strategy based on an unprecedented carbon-14 parallel screening was elaborated and applied to the SAW procedure in the perspective of determining at a glance the radiolabeling practicability of complex polyfunctionalized molecules.

\section{Results and Discussion}

\section{Assessment of the reaction applicability and development of a parallel ${ }^{14} \mathrm{C}$-screening technology}

To rapidly assess the generality and potential applicability of an intermolecular SAW with $\mathrm{CO}_{2}$, we developed a unique ${ }^{14} \mathrm{C}$-screening technology $\left({ }^{14} \mathrm{CO}_{2} /\right.$ Screen, Scheme $\left.2 \mathrm{~A}\right)$.

Four azides (S1 to S4) and five amines (I to $\mathbf{V}$ ) were selected based on their different electronic and steric nature (Scheme 2B), thus providing a representative overview of structures found in pharmaceutically relevant ureas (Scheme $1 \mathrm{~A}$ ). Specifically, we aimed to consider the following combinations: (a) alkyl azide with alkyl amine (b) alkyl azide with aryl amine (c) aryl azide with alkyl amine and (d) aryl azide with aryl amine.

${ }^{14} \mathrm{CO}_{2} /$ Screen was implemented by synergically merging the RC Tritec technology, for precise delivery of $\left[{ }^{14} \mathrm{C}\right] \mathrm{CO}_{2}$ and the multi-sample high throughput screening reactor CAT24. The 20 azide-amine couples (ratio 1:1) were screened in DMF according to standard SAW labeling conditions. ${ }^{19}$ One equivalent of $\mathrm{PPhMe}_{2}$ phosphine was added in each vial and a precise amount of labeled $\left[{ }^{14} \mathrm{C}\right] \mathrm{CO}_{2}$ was delivered in the reactor (Scheme 2A, see SI for the detailed experimental procedure). After two hours, unreacted $\left[{ }^{14} \mathrm{C}\right] \mathrm{CO}_{2}$ was removed and the crude reaction mixtures analyzed by scintillation counting, to quantify the residual ${ }^{14} \mathrm{C}$ radioactivity inside each reaction vial, and subsequently coupled to a RadioHPLC/MS to provide a quantitative assessment of the radiochemical conversion (RCC) of each vial.

When the aliphatic benzyl azide $\mathbf{S} 1$ was used, the corresponding linear urea was detected with aliphatic amine I and II in 59\% and 35\% RCC, respectively (Scheme $2 \mathrm{C}$ ). In presence of aniline III, the unsymmetrical linear urea S1-III was obtained in only $10 \%$ RCC, while another radioactive by-product was detected in the same amount (11\% RCC). The by-product was identified as the symmetrical benzyl urea generated from the addition of benzyl amine, formed by the Staudinger reduction of $\mathbf{S 1}$ under the reaction conditions, to the C-labeled isocyanate. When electron deficient aniline IV or secondary aniline $\mathbf{V}$ were screened, the desired products S1-IV and S1-V were not formed and only the labeled symmetrical benzyl urea was observed. When aromatic azides were utilized, a dramatic decrease of the reactivity was witnessed. Limited RCC was detected with sec-butylamine I (9 to 30\%). Unfortunately, negligible RCC occurred with the remaining combinations (Scheme 2C). Traces of symmetrical aromatic ureas was also detected in presence of azide $\mathbf{S} \mathbf{3}$ and $\mathbf{S 4}$ with aniline derivatives III, IV and V.

These results clearly show the limitations of the current intermolecular SAW protocol. Specifically, the presence of aromatic amines and azides seriously prevents the reactivity and undermine its generality. To increase its compatibility with various combinations of azides and amines, specific optimizations were necessary. 


\section{Optimization of the reaction and investigation of the scope}

At first, we explored the SAW procedure with a combination of aliphatic azides and aliphatic amines (Scheme $3 \mathrm{~A}$ ). The reaction was performed on model substrates benzylazide and $s$-butylamine in acetonitrile, in presence of one equivalent of $\mathrm{PPhMe}_{2} \cdot\left[{ }^{13} \mathrm{C}\right] \mathrm{CO}_{2}$ was utilized as a cheaper ${ }^{14} \mathrm{C}$-surrogate, and its precise addition was monitored utilizing a RC Tritec manifold, under identical conditions as for ${ }^{14} \mathrm{C}$. Introduction of $\left[{ }^{13} \mathrm{C}\right] \mathrm{CO}_{2}$ resulted in rapid formation of expected urea $\left[{ }^{13} \mathrm{C}\right] 6$ at room temperature in less than 5 minutes in $84 \%$ isolated yield. The procedure is tolerant towards sterically bulky dicyclohexylamine and chemoselectivity for aliphatic amine in respect to alcohols: ureas $\left[{ }^{13} \mathrm{C}\right] 7$ and $\left[{ }^{13} \mathrm{C}\right] 8$ were isolated in 73 and $51 \%$ yield. The use of a dipeptide was suitable and the corresponding ${ }^{13} \mathrm{C}$ urea $\left[{ }^{13} \mathrm{C}\right] 9$ synthesized with $51 \%$ isolated yield. Varying the nature of the azide did not affect the reaction. Secondary cycloalkyl azide provided $\left[{ }^{13} \mathrm{C}\right] 10$ in $55 \%$ yield. It is worth to indicate that in all the reactions performed, no parasite formation of symmetrical urea was observed in ${ }^{13} \mathrm{C}-\mathrm{NMR}$ of the crude mixture.

In light with these results, we subsequently explored the SAW procedure in presence of aromatic azides (Scheme 3B). The use of 1-naphtylazide afforded the unsymmetrical urea $\left[{ }^{13} \mathrm{C}\right] 12$ with an isolated yield of $69 \%$. The presence of electron donating groups like methoxy $\left[{ }^{13} \mathrm{C}\right] 13$, or benzyl $\left[{ }^{13} \mathrm{C}\right] \mathbf{2 1}$, are tolerated and the corresponding ureas were isolated in $77 \%$ and $62 \%$ yield. 3 -azidopyridine provided the corresponding product $\left[{ }^{13} \mathrm{C}\right] 14$ in $85 \%$ yield. On the other hand, the presence of electron withdrawing groups on the aromatic azide negatively impacted the outcome of the reaction. When 4trifluoromethyl and 4-methylbenzoate azides were utilized, the corresponding ureas were isolated only in moderate yields of $46 \%$ and $44 \%$, respectively. The anilines corresponding to the hydrolysis of the iminophosphorane (IP) intermediates were observed as major by-products of the transformation. In presence of stronger electron withdrawing groups (EWG) such as cyano or nitro, only the aniline byproducts were recovered and no traces of the desired ureas were observed. To prevent the hydrolysis of the IP, the reactions were performed under strict anhydrous conditions in the glovebox using deuterated solvent. Under such conditions, we could observe the formation of the expected urea by ${ }^{13} \mathrm{C}-\mathrm{NMR}$, but the major product detected in the reaction was the IP intermediate ( ${ }^{31} \mathrm{P}-\mathrm{NMR}$ ? $=11.9$ ppm). These results highlight the poor nucleophilic nature of IPs bearing EWGs, which are more prone to hydrolysis than nucleophilic attack to $\mathrm{CO}_{2}$. 


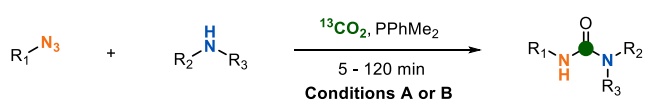

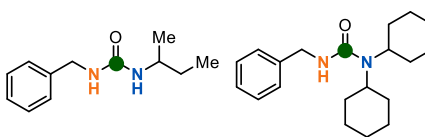

$\left[{ }^{13} \mathrm{C}\right] 6,84 \%, \mathrm{~A}$ $\left[{ }^{13} \mathrm{C}\right] 7,73 \%, \mathbf{A}$

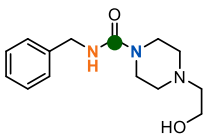

$\left[{ }^{13} \mathrm{C}\right] 8,51 \%, \mathrm{~A}$

\section{If}

$\left[{ }^{13} \mathrm{C}\right] 9,51 \%, \mathrm{~A}$

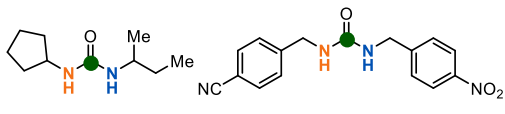

$\left[{ }^{13} \mathrm{C}\right] 10,55 \%, \mathbf{A}$ $\left[{ }^{13} \mathrm{C}\right] 11,84 \%, \mathbf{A}$

B - Aryl azide / Alkyl amine

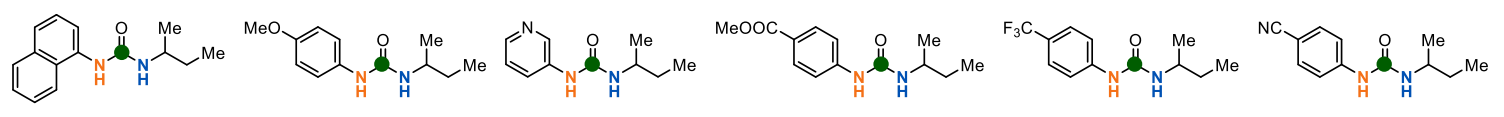

$\left[{ }^{13} \mathbf{C}\right] 13,77 \%, \mathbf{A}$

$\left[{ }^{13} \mathrm{C}\right] 14,85 \%$, A

$\left[{ }^{13} \mathrm{C}\right] 15,44 \%$, A

$\left[{ }^{13} \mathrm{C}\right] 16,46 \%$, A

$\left[{ }^{13} \mathrm{C}\right] 17,73 \%, \mathbf{A}^{\mathrm{a}}$

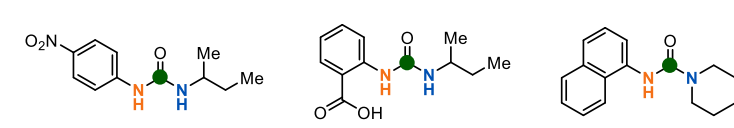

$\left[{ }^{13} \mathrm{C}\right] 18,68 \%, \mathbf{A}^{\mathrm{a}}$

$\left[{ }^{13} \mathbf{C}\right] 19,0 \%, \mathbf{A}$

$\left[{ }^{13} \mathrm{C}\right] 20,53 \%, \mathrm{~A}$

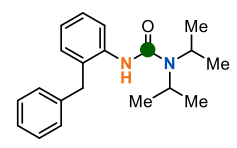

$\left[{ }^{13} \mathrm{C}\right] 21,62 \%, \mathrm{~A}$

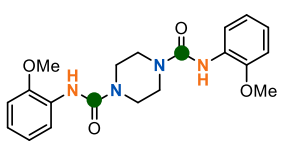

$\left[{ }^{13} \mathbf{C}\right] 22^{b}, 34 \%, A^{b}$

C - Late-stage drugs diversification

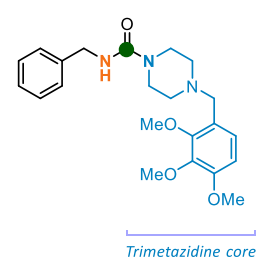

$\left[{ }^{13} \mathbf{C}\right] 23^{d}, 60 \%, A^{c}$

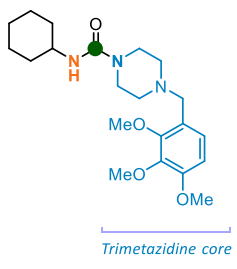

$\left[{ }^{13} \mathrm{C}\right] 24,44 \%, \mathbf{A}^{\mathrm{c}}$

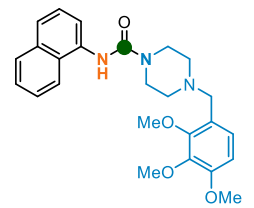

Trimetazidine core

$\left[{ }^{13} \mathrm{C}\right] 25,77 \%, \mathbf{A}^{\mathrm{c}}$

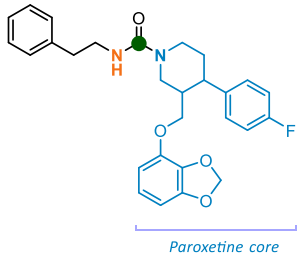

$\left[{ }^{13} \mathbf{C}\right] 26,70 \%, \mathbf{A}^{\mathrm{d}}$

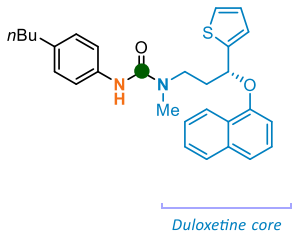

$\left[{ }^{13} \mathbf{C}\right] 27,83 \%, \mathbf{A}^{\mathrm{d}}$

D - Aryl azide / Aryl amine

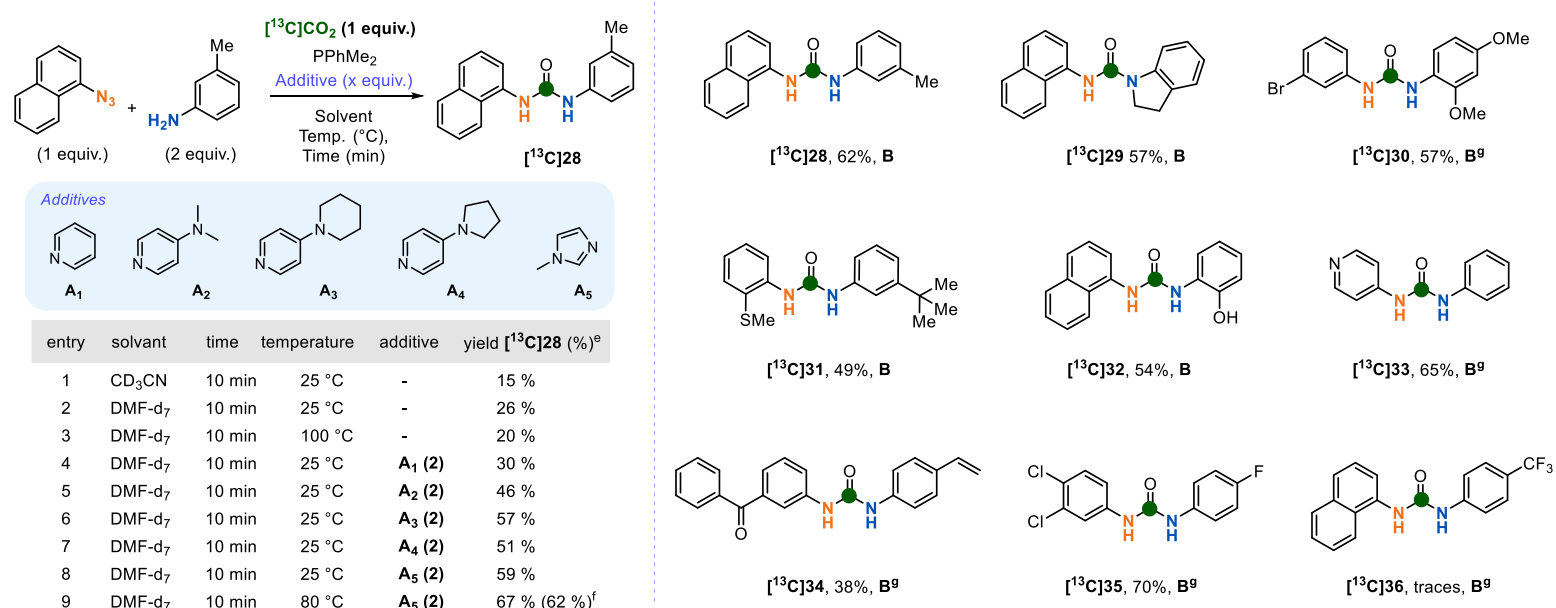

Scheme 3. Scope of the reaction. Green colored circles denotes the position of the carbon atoms labeled. Reaction conditions: $\mathrm{A} / \mathrm{azide}(0.1$ mmol, 1 equiv.), amine (0.1 mmol, 1 equiv.), $\mathrm{PPhMe}_{2}\left(0.1 \mathrm{mmol}, 1\right.$ equiv.), $\left[{ }^{13} \mathrm{C}\right] \mathrm{CO}_{2}$ (1.1 equiv.), $\mathrm{CH}_{3} \mathrm{CN}(0.6 \mathrm{~mL}), 5 \mathrm{~min}, 25^{\circ} \mathrm{C} . \mathrm{B} /$ azide $(0.1 \mathrm{mmol}$, 1 equiv.), amine ( $0.2 \mathrm{mmol}, 2$ equiv.), $N$-methylimidazole $\left(0.2 \mathrm{mmol}, 2\right.$ equiv.), $\mathrm{PPhMe} 2(0.1 \mathrm{mmol}, 1 \mathrm{equiv}),.\left[{ }^{13} \mathrm{C}\right] \mathrm{CO}_{2}(1.1 \mathrm{equiv}$.), $\mathrm{DMF}(0.6 \mathrm{~mL})$, $10 \mathrm{~min}, 80^{\circ} \mathrm{C}$. [a] $70{ }^{\circ} \mathrm{C}$ instead of $25^{\circ} \mathrm{C}$, [b] azide $(0.2 \mathrm{mmol}, 2$ equiv. $)$, amine $(0.1 \mathrm{mmol}, 1$ equiv. $\left.), \mathrm{PPhMe}_{2}(0.2 \mathrm{mmol}, 2 \mathrm{equiv}),{ }^{13} \mathrm{C}\right] \mathrm{CO}_{2}(2.2$ equiv.) [c] DIPEA (2 equiv.) was added. [d] DIPEA (1 equiv.) was added. [e] NMR yield, MTBE was used as internal standard. [f] Isolated yield. [g] 2 hours instead of $10 \mathrm{~min}$. 


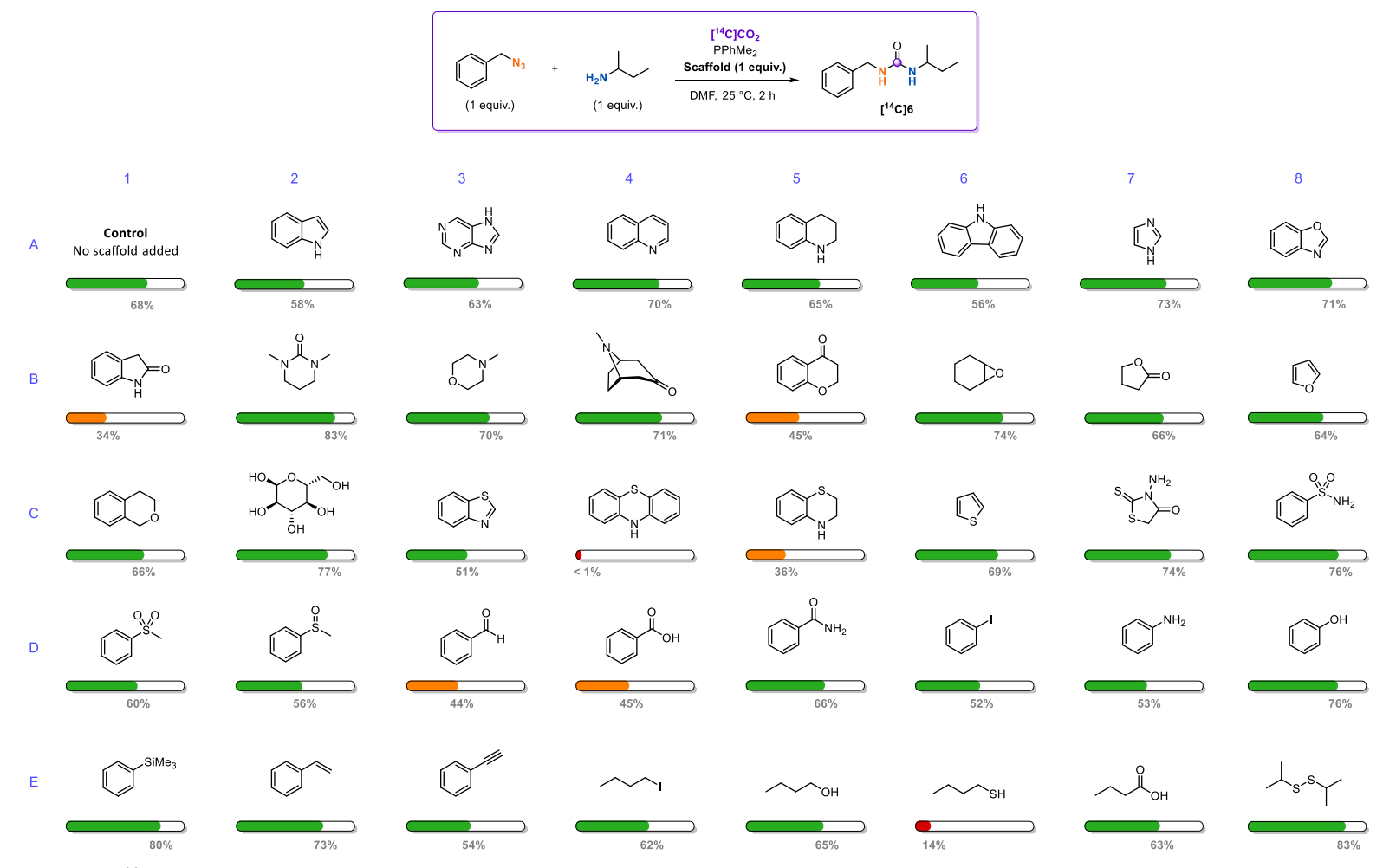

Scheme 4. ${ }^{14} \mathrm{C}$-Robustness screening. Effect exerted by various additives on the SAW procedure. The compatibility of each additive was calculated using the ${ }^{14} \mathrm{CO}_{2} /$ Screen procedure developing. Colored bars (red $\mathrm{RCC}<20 \%$, orange $20 \%<\mathrm{RCC}<50 \%$, green $\mathrm{RCC}>50 \%$ ).

In order to favor the aza-Wittig step, the procedure was reproduced in the glovebox and the reaction heated at $70{ }^{\circ} \mathrm{C}$ for 10 minutes. By simply adapting the protocol, it was possible to isolate the corresponding linear ureas $\left[{ }^{13} \mathrm{C}\right] 17$ and $\left[{ }^{13} \mathrm{C}\right] 18$ in $73 \%$ and $68 \%$ yield, respectively. On the other hand, ortho-azidobenzoic acid was not suitable for this procedure. After addition of the phosphine, the carboxylate stabilized the IP forming a 6-members ring that prevented the aza-Wittig reaction with $\mathrm{CO}_{2}\left(\left[{ }^{13} \mathrm{C}\right] 19\right.$ not observed). In presence of a diamine such as piperazine, a double SAW took place in presence of two equivalents of phosphine, azide and $\left[{ }^{13} \mathrm{C}\right] \mathrm{CO}_{2}$ and bis-urea $\left[{ }^{13} \mathrm{C}\right] \mathbf{2 2}$ was isolated in $34 \%$. Though this result was not optimized further, it paves the way for the development of high molar activity carbon-14 labeling strategies. Finally, the direct diversification of drugs using various aliphatic and aromatic azides was performed. The three commercially available pharmaceuticals Trimetazidine, Paroxetine and Duloxetine were easily functionalized, in presence of one single equivalent of carbon dioxide in $44 \%$ to $83 \%$ yield (Scheme 3 C).

With these results in hand, we next explored the SAW in the presence of less nucleophilic aniline derivatives (Scheme 3D). When standard conditions were utilized with $m$-toluidine, the expected urea $\left[{ }^{13} \mathrm{C}\right] 28$ was obtained in poor yield, in agreement with what highlighted by the ${ }^{14} \mathrm{CO}_{2} / \mathrm{Screen}$. The use of DMF as solvent and higher temperatures slightly improved the yield (Scheme 3D, entrees 2 and 3).

In order to increase the electrophilicity of the transient isocyanate, we decided to investigate the use of various additives. Addition of DMAP $\left(A_{2}\right)$ to the reaction mixture provided $\left[{ }^{13} \mathrm{C}\right] \mathbf{2 8}$ in $46 \%$ yield (entry 5). Other pyridine derivatives significantly increase the yield of $\left[{ }^{13} \mathrm{C}\right] \mathbf{2 8}$ (entries 4 to 7). Finally, $\mathrm{N}$ methylimidazole $\left(\mathbf{A}_{5}\right)$ was identified as most suitable additive, affording the expected compound in ten minutes at $80^{\circ} \mathrm{C}$ in $62 \%$ isolated yield (entry 9).

We next investigated the scope of this new procedure for bis-aromatic ureas preparation (Scheme 3D). As expected, electron-donating anilines reacted smoothly affording the labeled unsymmetrical urea 
$\left[{ }^{13} \mathrm{C}\right] \mathbf{2 8 - 3 1}$ in presence of both primary and secondary amines. Interestingly, the SAW exhibited high chemoselectivity toward aniline in respect of phenol: $\left[{ }^{13} \mathrm{C}\right] 32$ was isolated in $54 \%$ yield and no traces of carbamate was detected in the reaction crude. Linear urea labeling was also possible with poor electron withdrawing aniline leading to aromatic ureas $\left[{ }^{13} \mathrm{C}\right] 34$ and $\left[{ }^{13} \mathrm{C}\right] 35$. However, in presence of strong electron-withdrawing anilines, the reaction did not occur and the expected urea $\left[{ }^{13} \mathrm{C}\right] 36$ was not observed.

It is noteworthy to highlight that the current protocol is of interest not only in the field of carbon isotope labeling, but also compared to other state of the art methodologies for the synthesis of ureas directly from $\mathrm{CO}_{2}$. For example, the group of Stephan described in 2019 the synthesis of urea derivatives from $\mathrm{CO}_{2}$ and silylamines. ${ }^{14 \mathrm{~b}}$ While very effective, this procedure is applicable only to symmetrical ureas, is performed at $120-150^{\circ} \mathrm{C}$ and utilized undetermined excess of $\mathrm{CO}_{2}$ ( 2 to $\left.5 \mathrm{~atm}\right) .{ }^{20}$

\section{Robustness screening: de-risking the SAW}

Understanding the practical limitations of a chemical transformation is a milestone for efficiently planning the synthesis of a desired compound of interest. This is even more critical in radioisotope labeling where costs, related to the isotope source and waste disposal, severely impact the choice of retrosynthetic strategies. ${ }^{2}$ Nonetheless, published reports of the scope of novel transformations are often biased towards the more successful results and lack of information on the compatibility with functional groups and tolerance to heterocycles, thus severely restraining the capacity to foretell reaction outcomes for undescribed substrates.

With the aim of de-risking the SAW and applying it to relevant pharmaceutical molecules, we decided to evaluate its robustness. This valuable approach, introduced by the work of Glorius in $2013,{ }^{21}$ and not frequently encountered since, ${ }^{22}$ was applied once in radiochemistry by the group of Gouverneur with fluorine-18. ${ }^{23,24}$ The advantage of such a strategy is that it only takes a glance to predict the success of the labeling on a complex molecule, thus significantly reducing the time invested in the assembly of reaction precursors. To realize this de-risking approach, we took advantage of the ${ }^{14} \mathrm{CO}_{2} /$ Screen previously implemented and we selected the formation of urea $\left[{ }^{14} \mathrm{C}\right] 6$ as model reaction.

Equimolar amounts of 1-naphtylazide, sec-butylamine and phosphine were added in the mixture, in presence of one molar equivalent of a molecular fragment, likely to interfere. The reaction was performed using $\left[{ }^{14} \mathrm{C}\right] \mathrm{CO}_{2}$ and coupled to scintillation counting and radio HPLC, providing the RCC of each reaction. Additives were selected based on the work of Njardarson, where the most frequent nitrogen heterocycles, oxygen heterocycles and sulfur-containing groups in FDA approved drugs are tallied. ${ }^{25}$

As shown in Scheme 4, most of the nitrogen-containing heterocycles (A2-A8, B2-B4, C3) screened were compatible with the reaction and no impact on the radiolabeling was observed.

Oxygen containing heterocycle (B3, B5-C2) were also well tolerated and even the challenging unprotected $\mathrm{D}-(+)$-glucose $\mathbf{C 2}$, one of the major components found in pharmaceuticals, was suitable. However, in presence of some carbonyl-containing functional groups lower conversions were observed. Imine formation with benzaldehyde D3 or chromanone B5 and acido-basic reaction with carboxylic acid D4 could parasite the reaction.

The presence of sulfur derivatives was also investigated. Chemical functions such as sulfone D1 sulfoxide D2 and sulfonamide $\mathbf{C} 8$ had no impact on the labeling of the linear urea, affording $\left[{ }^{14} \mathbf{C}\right] \mathbf{6}$ with 
similar RCC to the control experiment. However, the RCC was dramatically affected when phenothiazine $\mathbf{C} 4$ was present as additive and no radioactive compound was detected by radioHPLC.

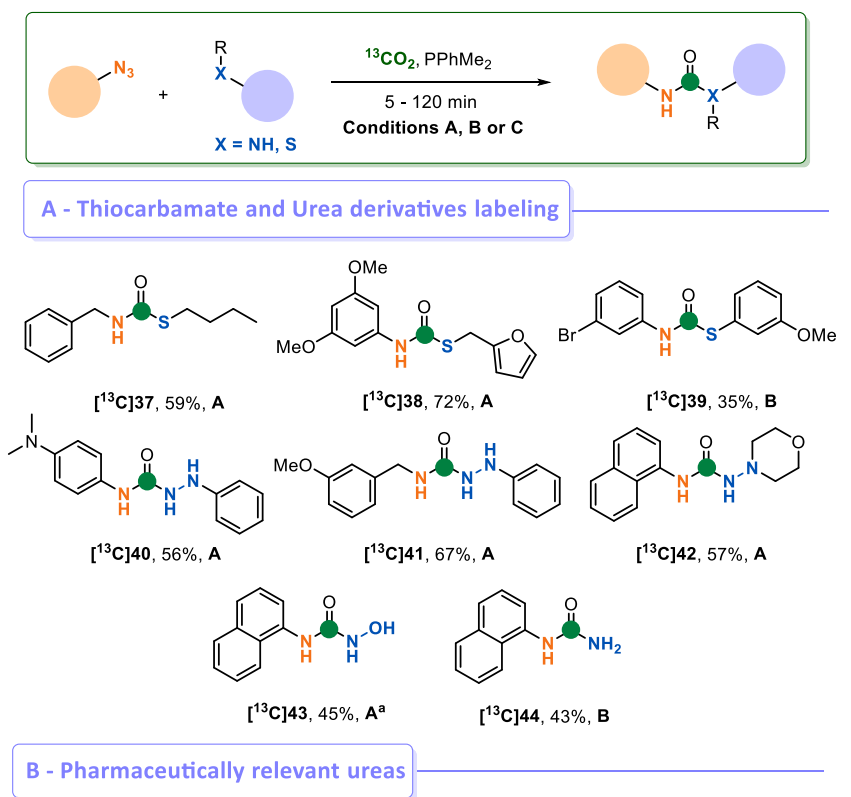

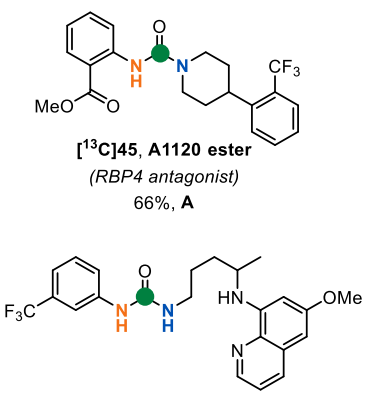

$\left[{ }^{13} \mathrm{C}\right] 47$, Primaquine analogue<smiles>COc1ccccc1NC(=O)Nc1ccc(-c2cnn(C)c2)cc1</smiles>

$\left[{ }^{13} \mathrm{C}\right] 49$, (tau aggregation inhibitor)
$36 \%, \mathbf{B}$<smiles>Cc1ccccc1NC(=O)N1CCCC1C(=O)O</smiles>

(i) $\left[{ }^{13} \mathrm{C}\right] 51, \mathrm{R}=\mathrm{CH}_{3}: 64 \%$, A

(i) $\longrightarrow\left[{ }^{13} \mathrm{C}\right] 52, \mathbf{R}=\mathrm{H}: 95 \%$ $\left(\alpha_{4} \beta_{1}\right.$.agonist)<smiles>CC(C)(C)NCC(O)COc1ccc(NC(=O)NC2CCCCC2)cc1</smiles>

$\left[{ }^{13} \mathrm{C}\right] 46$, Talinolol (beta blocker)<smiles>O=C(Nc1cccnc1)N1CCN(Cc2ccc(Oc3ccc(Cl)cc3)cc2)CC1</smiles>

$\left[{ }^{13} \mathrm{C}\right] 48, \mathrm{JNJ}-40355003$ analogue<smiles>CNC(=O)c1cc(Oc2ccc(NC(=O)Nc3ccc(Cl)c(C(F)(F)F)c3)cc2)ccn1</smiles>

$\left[{ }^{13} \mathrm{C}\right] 50$, Sorafenib (kinase inhibitor)<smiles>COc1ccccc1N1CCN(CCCNC(=O)NN(Cc2ccccc2)c2ccccc2)CC1</smiles><smiles>COc1ccc(Cl)cc1C(=O)NCCc1ccc(S(=O)(=O)NC(=O)NC2CCCCC2)cc1</smiles>

Scheme 5. Application of the SAW to thiocarbamate, urea derivatives and pharmaceuticals. Green colored circles denotes the position of the carbon atoms labeled. Reaction conditions: $\mathrm{A} /$ azide $\left(0.1 \mathrm{mmol}, 1\right.$ equiv.), amine $\left(0.1 \mathrm{mmol}, 1\right.$ equiv.), $\mathrm{PPhMe}_{2}(0.1 \mathrm{mmol}, 1 \mathrm{equiv}),.\left[{ }^{13} \mathrm{C}\right] \mathrm{CO}{ }_{2}(1.1$ equiv.), $\mathrm{CH}_{3} \mathrm{CN}(0.6 \mathrm{~mL}), 5 \mathrm{~min}, 25^{\circ} \mathrm{C}$. B / azide ( $0.1 \mathrm{mmol}, 1$ equiv.), amine ( $0.2 \mathrm{mmol}, 2$ equiv. $), \mathrm{N}$-methylimidazole $(0.2 \mathrm{mmol}, 2$ equiv.), PPhMe 2 (0.1 mmol, 1 equiv.), $\left[{ }^{13} \mathrm{C}\right] \mathrm{CO}_{2}\left(1.1\right.$ equiv.), $\mathrm{DMF}(0.6 \mathrm{~mL}), 120 \mathrm{~min}, 80^{\circ} \mathrm{C}$. C/ azide $(0.1 \mathrm{mmol}, 1$ equiv. $)$, amine $(0.1 \mathrm{mmol}, 1 \mathrm{equiv}$.), $\mathrm{NaH}(0.2 \mathrm{mmol}$, 2 equiv.) $\mathrm{PPhMe}_{2}\left(0.1 \mathrm{mmol}, 1\right.$ equiv.), $\left[{ }^{13} \mathrm{C}\right] \mathrm{CO}_{2}$ (1.1 equiv.), DMF $(0.6 \mathrm{~mL}), 5 \mathrm{~min}, 80^{\circ} \mathrm{C}$. [a] 3 equivalents of DIPEA was added, [b] 5 equivalents of cyclohexylamine was added instead of one. (i) $\mathrm{LiOH}, \mathrm{THF} / \mathrm{H}_{2} \mathrm{O}(2 / 1), 25{ }^{\circ} \mathrm{C}, 18 \mathrm{~h}, 95 \%$. 
It is worth to note, that while disulfide E8 did not affect the transformation, the use of butanethiol E6 showed low radio chemical conversion indicating the presence of a competitive reaction. RadioHPLC/MS allowed to identify the thiocarbamate as major product of the reaction (radio-HPLC ratio: $4 / 1$ ). Overall, this robustness screening chemical showed a good tolerance and chemoselectivity toward a whole range of chemical functions investigated, thus providing guidance for future applications.

\section{Access to other derivatives}

At first, we looked into aliphatic thiols and thiophenols. Pleasingly, under the same conditions, three thiocarbamates $\left[{ }^{13} \mathrm{C}\right] \mathbf{3 7 - 3 9}$ were isolated in 35 to $72 \%$ yield. We next investigated the labeling of semicarbazides: one of the building blocks to conduct to semicarbazones, an important family known for its anti-viral properties, anti-cancer activity and its ability to chelate metals. ${ }^{26}$ To the best of our knowledge, no radiochemical procedure has been described for radio-carbonylation of this family of derivatives. To access to non-isotopically labeled semicarbazides, two main chemical pathways are described. Most commonly, they are obtained by nucleophilic addition of hydrazide derivative onto isocyanates, commercially available or generated in situ from phosgene, Curtius rearrangement or hydrogen carbonate. ${ }^{27}$

As shown in Scheme 5A, the use of both aromatic and aliphatic hydrazines enabled accessing to ${ }^{13} \mathrm{C}$ labeled semicarbazides $\left[{ }^{13} \mathrm{C}\right] \mathbf{4 0 - 4 2}$ in 56 to $67 \%$ yield, using the standard conditions. To access to $1-$ hydroxy-3-(naphthalen-1-yl)urea $\left[{ }^{13} \mathrm{C}\right] \mathbf{4 3}$, hydroxylamine hydrochloride was utilized as nitrogen source in presence of DIPEA. Pleasingly, enrichment was observed in ${ }^{13} \mathrm{C}-\mathrm{NMR}$ corresponding to the expected hydroxyurea, which was next isolated in $45 \%$ yield. Applying the same conditions in presence of ammonium chloride was not successful to obtain terminal urea $\left[{ }^{13} \mathrm{C}\right] 44$. The utilization of a commercially available solution of ammonia in methanol as nitrogen source assisted by $\mathrm{N}$ methylimidazole at $80^{\circ} \mathrm{C}$ allowed to isolate the desired terminal urea in $43 \%$ yield. This moderate yield can be explained by the hydrolysis of the starting azide and the recovery of the corresponding aniline. Nonetheless, this procedure allows to access to terminal ureas in one single operation from $\mathrm{CO}_{2}$ with no need of protecting groups.

\section{Carbon labeling of pharmaceutically relevant urea derivatives}

Driven by these results, a series of representative pharmaceutical ureas were labeled starting from appropriate combinations of azides and amines (Scheme 5B). A1120 is an inhibitor of Retinol Binding Protein 4 (RBP4) reported by Amgen in 2009. ${ }^{28}$ Taking into consideration the previous limitation observed on substrate 19, we started from the ortho-carboxylic acid protected azide and, under SAW procedure, $\left[{ }^{13} \mathrm{C}\right] 45$ was isolated with $66 \%$ yield. Next, we focused on Talinolol 46 . The structure of this beta blocker was particularly interesting as its labeling would provide a severe challenge using phosgene or the Mitsunobu/BEMP strategies, given the presence of the beta-hydroxyl amine side chain. On the other hand, the SAW enabled to obtain $\left[{ }^{13} \mathrm{C}\right] 46$ in a fully chemo-selective and high yielding manner. $\left[{ }^{13} \mathrm{C}\right] 47$, a primaquine analogue, ${ }^{29}$ and $\left[{ }^{13} \mathrm{C}\right] 48$, a positional isomer of JNJ-40355003, an inhibitor of the Fatty Acid Amide Hydrolase (FAAH) ${ }^{30}$ were synthesized in $32 \%$ to $91 \%$ yield, respectively. Aromatic urea $\left[{ }^{13} \mathrm{C}\right] 49$, patented by Merck as potential tau aggregation inhibitor in Alzheimer disease, ${ }^{31}$ was obtained in $36 \%$ yield, while kinase inhibitor Sorafenib $\left[{ }^{13} \mathrm{C}\right] 50$ in $47 \%$ yield in presence of $\mathrm{N}$-methylimidazole. Urea $\left[{ }^{13} \mathrm{C}\right] 52$, an $]_{4}[]_{1}$ integrin agonist reported by Spampinato and 
Giacomini in 2019, ${ }^{32}$ was obtained from L-proline methyl ester and 2-azidotoluene following by saponification in $61 \%$ yield over two steps.

Next, semicarbazide $\left[{ }^{13} \mathrm{C}\right] 46$, recently described as a full agonist of the $\mathrm{D}_{4}$ receptor, ${ }^{33}$ was labeled with $66 \%$ yield. This example illustrate the use of the SAW as a convergent alternative for the synthesis of such analogues. Finally, antidiabetic sulfonylurea Glyburide $\left[{ }^{13} \mathrm{C}\right] \mathbf{4 8}$ was labeled for the first time on the carbonyl position. After deprotonation of the corresponding sulfonamide with sodium hydride, the sequence successfully provided the labeled urea with $40 \%$ yield using cyclohexylazide as the other partner.

\section{Carbon-14 Radioisotope Labeling}

To evaluate the potential of this methodology and to assess its compliance to the recommendations for late-stage labeling, commercially available pharmaceutical drugs were labeled using high molar activity $\left[{ }^{14} \mathrm{C}\right] \mathrm{CO}_{2}\left(\mathrm{Am}_{\mathrm{m}}: 2.17 \mathrm{GBq} \cdot \mathrm{mmol}^{-1}\right)$. In agreement with the results obtained with carbon 13 isotope, four drugs and analogues were labeled with carbon 14 in high molar activities, negligible isotope dilution and high radiochemical purities (Scheme 6). Talinolol $\left[{ }^{14} \mathrm{C}\right] 47$ was labeled with a significant molar activity of $2.05 \mathrm{GBq} \cdot \mathrm{mmol}^{-1}$ and $82 \%$ yield.
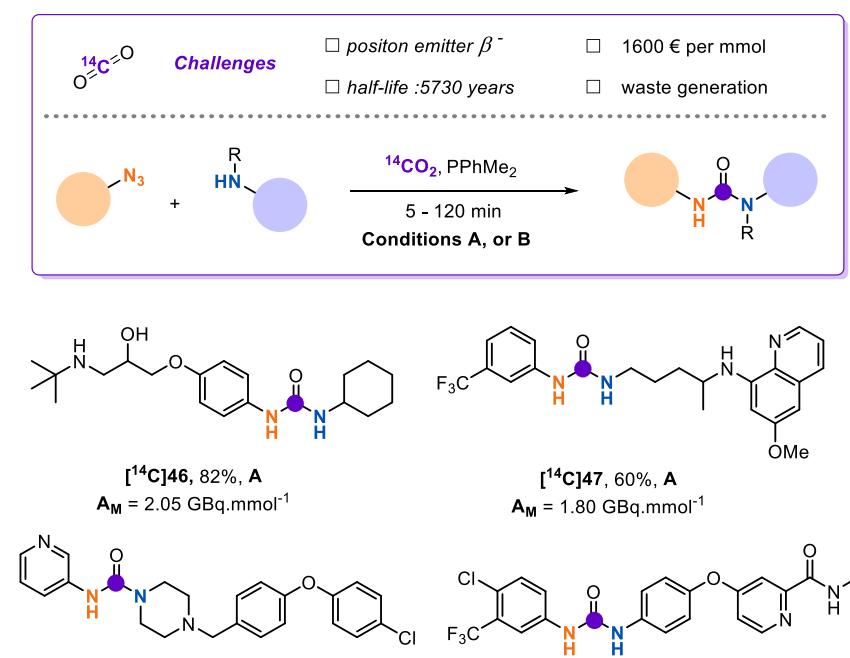

$\left[{ }^{14} \mathrm{C}\right] 47,60 \%, \mathrm{~A}$

$\mathbf{A}_{\mathbf{M}}=1.80 \mathrm{GBq} \cdot \mathrm{mmol}^{-1}$

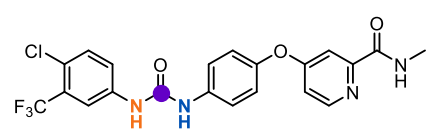

$76 \%, A$

$\left[{ }^{14} \mathrm{C}\right] 50,26 \%, B$

$A_{M}=2.07$ GBq.mmol ${ }^{-1}$

Scheme 6: ${ }^{14} \mathrm{C}$ Late-stage carbon isotope labeling of pharmaceutically relevant linear ureas. Purple colored circles denotes the position of the carbon atoms labeled. Reaction conditions: A / azide ( $0.1 \mathrm{mmol}, 1$ equiv. $)$, amine $\left(0.1 \mathrm{mmol}, 1\right.$ equiv.), $\mathrm{PPhMe}_{2}(0.1 \mathrm{mmol}, 1$ equiv.), $\left.{ }^{14} \mathrm{C}\right] \mathrm{CO}_{2}$ (1.1 equiv.), $\mathrm{CH}_{3} \mathrm{CN}(0.6 \mathrm{~mL}), 5 \mathrm{~min}, 25^{\circ} \mathrm{C}$. B / azide $(0.1 \mathrm{mmol}, 1$ equiv.), amine $(0.2 \mathrm{mmol}, 2$ equiv.), $N$-methylimidazole $(0.2 \mathrm{mmol}, 2$ equiv.), $\mathrm{PPhMe}_{2}\left(0.1 \mathrm{mmol}, 1\right.$ equiv.), $\left[{ }^{13} \mathrm{C}\right] \mathrm{CO}_{2}$ (1.1 equiv.), $\mathrm{DMF}(0.6 \mathrm{~mL}), 120 \mathrm{~min}, 80^{\circ} \mathrm{C}$.

Primaquine analogue $\left[{ }^{14} \mathrm{C}\right] 47$ and $\mathrm{FAAH}$ inhibitor $\left[{ }^{14} \mathrm{C}\right] 48$ were respectively labeled with molar activities of $1.80 \mathrm{GBq} \cdot \mathrm{mmol}^{-1}$ and $1.94 \mathrm{GBq} \cdot \mathrm{mmol}^{-1}$ in $60 \%$ and $76 \%$ yields. Sorafenib used in chemotherapy to treat kidney, liver, and thyroid cancer has been previously labeled using carbon 11 using phosgene. ${ }^{34}$ Here, we show that this methodology open access to other radioactive carbon isotope such as carbon14 for the labeling of drugs such as Sorafenib $\left[{ }^{14} \mathrm{C}\right] 50$ obtained with a molar activity of $2.07 \mathrm{GBq} . \mathrm{mmol}^{-}$ 1 , opening a gateway to study their metabolism. 


\section{Carbon-11 Radioisotope Labeling}

Based on the short reaction time associated to the SAW procedure, application to ${ }^{11} \mathrm{C}$-labeling seemed promising. Nonetheless, a series of challenges have to be faced: the high energy ${ }^{+}$emission that require the use of specialized automated systems, the minute concentrations of $\left[{ }^{11} \mathrm{C}\right] \mathrm{CO}_{2}$ produced in the cyclotron and its short half-life $(20.4 \mathrm{~min}) \cdot{ }^{35}$ Despite the diametrically different technical environment compared to carbon-14 and the $\mathrm{CO}_{2}$ stoichiometry, model substrate $\left[{ }^{11} \mathrm{C}\right] 6$ could be effectively labeled in $63 \%$ RCC, by simply adapting the procedure (Scheme 7). With the SAW approach, the non-purified $\left[{ }^{11} \mathrm{C}\right] 6$ could be synthesized in only 10 minutes. Considering the robustness of the method even when the challenging carbon-11 isotope is concerned, we next decided to label Talinolol. As its structure lack of methyl moieties, radiomethylation of this beta blocker would not be feasible for ${ }^{11} \mathrm{C}$ labeling. Under standard conditions, $\left[{ }^{11} \mathrm{C}\right] 46$ was isolated in $26 \pm 6 \% \mathrm{RCY}$ and high molar activity $\left(A_{m}, 55 \pm 10 \mathrm{GBq} \mu \mathrm{mol}^{-1}\right)$. To the best of our knowledge, carbonyl ${ }^{11} \mathrm{C}$-labeling of semicarbazides is unprecedented, thus compound $\mathbf{5 3}$ looked as an ideal example to explore this SAW application. Pleasingly, $\left[{ }^{11} \mathrm{C}\right] 53$ could be labeled in $31 \pm 4 \% \mathrm{RCY}$ with a $\mathrm{A}_{\mathrm{m}}$ of $70 \pm 8 \mathrm{GBq} \mu \mathrm{mol}^{-1}$. These preliminary examples of linear urea derivatives showcase that the SAW approach will broaden the scope of original ${ }^{11} \mathrm{C}$-labeled PET tracers available for imaging applications.

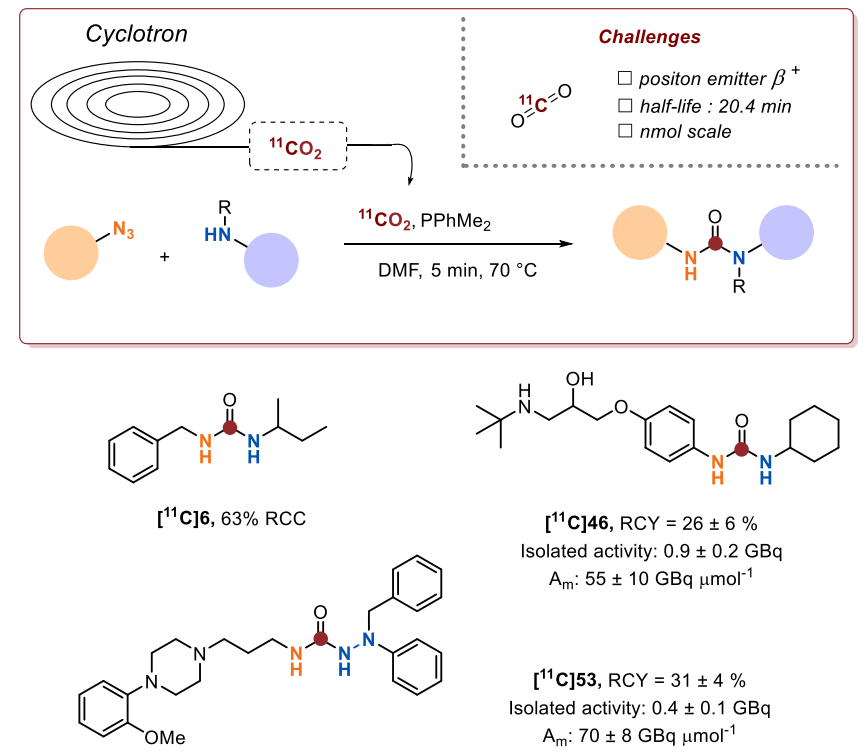

Scheme 7. Late-stage ${ }^{11} \mathrm{C}$-radiolabeling of pharmaceutically relevant linear ureas. RCY: decay-corrected radiochemical yield; $A_{m}$ : decay-corrected molar activity. See SI for experimental details.

\section{Conclusion}

Carbon isotope labeling is an effective technology to track the fate of organic compounds either in the environment or in living organisms. Given the ubiquitous presence of this element in nature, such traceless modification is virtually suitable to any organic compounds. Linear ureas and derivatives such as semicarbazides, sulfonylureas, hydroxyl ureas, or simple terminal ureas are pharmacophore moieties frequently present in biologically relevant molecules, including pharmaceuticals and agrochemicals. In this article, we reported a general Staudinger aza-Wittig (SAW) approach which enabled accessing all urea derivatives in a convergent and straightforward manner. This strategy was carefully developed utilizing $\mathrm{CO}_{2}$ as limiting reagent and has proven to be effective and compatible with all isotopes of carbon: ${ }^{13} \mathrm{C},{ }^{14} \mathrm{C}$ and ${ }^{11} \mathrm{C}$. As radiosynthesis with these isotopes is mostly performed when there is a need in preclinical or clinical developments, we have here provided general guidelines 
on scope and limitation of these reactions. All four possible combinations of aliphatic/aromatic azide/amines partners were studied in details so to generate a predictability for immediate application. In addition, a parallel screening was implemented to provide further information on the tolerance of the SAW with most representative heterocycles and functional groups found in FDA approved drugs. This empirical approach consists of evaluating the fluctuation in the outcome (RCC) of a reaction model in presence of such additives. This required the development of a technology utilizing $\left[{ }^{14} \mathrm{C}\right] \mathrm{CO}_{2}$ as radioactive screening agent, for the first time. Based on the knowledge developed herein, it was possible to label in one single and unique step nine pharmaceutically relevant molecules, including commercial drugs with carbon-13. The technology was validated on radiocarbon and four pharmaceuticals were labeled with ${ }^{14} \mathrm{C}$ in high molar activities, suitable for all possible applications in pharmaceutical industry. Finally, proof of concept was also obtained using short-lived ${ }^{11} \mathrm{C}$ : even the unprecedented labeling of a bioactive semicarbazide compound could be easily performed using this same method. The current work provides a general method for the labeling of urea derivatives which will fill a gap in the literature and provide robust alternative for diagnostic and drug development programs. Furthermore, the robustness screening based on $\left[{ }^{14} \mathrm{C}\right] \mathrm{CO}_{2}$ herein developed could be applied to de-risking other radiolabeling approaches, beyond this SAW reaction, thus providing rapid assessment of applicability of future radiolabeling technologies.

\section{Acknowledgements}

This project has received funding from the European Union's Horizon 2020 research and innovation program under the Marie Sklodowska-Curie grant agreement $\mathrm{N}^{\circ} 675071$ and the CEA. The authors thank David-Alexandre Buisson and Sabrina Lebrequier for the excellent analytical support.

\section{References}

[1] J. Atzrodt, V. Derdau, W. J. Kerr, M. Reid, Angew. Chem. Int. Ed. 2018, 57, 1758-1784.

[2] a) E. M. Isin, C. S. Elmore, G. N. Nilsson, R. A. Thompson, L. Weidolf, Chem. Res. Toxicol. 2009, 25, 532-542; b) C. S. Elmore, R. A. Bragg, Bioorg. Med. Chem. Lett. 2015, 25, 167-171; c) P. H. Marathe, W. C. Shyu, W. G. Humphreys, Curr. Pharm. Des. 2004, 10, 2991-3008; d) B. D. Maxwell, C. S. Elmore, Eds. Radiosynthesis for ADME studies; 461-471 (John Wiley \& Sons, Inc: Hoboken, 2012); e) C. S. Elmore, Ed. Annu. Rep. Med. Chem. 2009, 44, 515-534.

[3] a) P. M. Matthews, E.A. Rabiner, J. Passchier, R. N. Gunn, Br. J. Clin. Pharmacol. 2012, 73, 175186; b) N. Penner, L. Xu, Prakash, C. Chem. Res. Toxicol. 2012, 25, 513-531; c) S. M. Ametamey, M. Honer, P. A. Schubiger, Chem. Rev. 2008, 108, 1501-1516; d) P. W. Miller, N. J. Long, R. Vilar, A. D. Gee, Angew. Chem. Int. Ed. 2008, 47, 8998-9033.

[4] a) R. Voges, J. R. Heys, T. Moenius, Preparation of Compounds Labeled with Tritium and Carbon-14. 393 John Wiley \& Sons, Ltd, 2009; b) P. J. H. Scott, Angew. Chem. Int. Ed. 2009, 48, 60016004.

[5] For recent late-stage isotope labeling strategies see: a) J. Atzrodt, V. Derdau, W. J. Kerr, M. Reid, Angew. Chem. Int. Ed. 2018, 57, 3022-3047; b) M. Valero, D. Bouzouita, A. Palazzolo, J. Atzrodt, C. Dugave, S. Tricard, S. Feuillastre, G. Pieters, B. Chaudret, V. Derdau, V. Angew. Chem. Int. Ed. 2020, 59, 3517-3522; c) L. Trump, A. Lemos, B. Lallemand, P. Pasau, J. Mercier, C. Lemaire, A. Luxen, C. Genicot, Angew. Chem. Int. Ed. 2019, 58, 13149-13154; d) P. Xu, D. Zhao, F. Berger, A. Hamad, J. Rickmeier, R. Petzold, M. Kondratiuk, K. Bohdan, T. Ritter, Angew. Chem. Int. Ed. 2020, 59, 1956-1960. 
[6] a) P. Sikka, J. K. Sahu, A. K. Mishra, S. R. Hashim, Med. Chem. 2015, 5, 479-483; b) Ghosh, A. K.; Brindisi, M. J. Med. Chem. 2020, 63, 2751-2788.

[7] P. Ertl, E. Altmann, J. McKenna, J. Med. Chem. 2020, 63, 8408-8414.

[8] a) K. Dahl, C. Halldin, M. Schou, Clin. Transl. Imaging 2017, 5, 275-289; b) X. Deng, J. Rong, L. Wang, N. Vasdev, L. Zhang, L. Josephson, S. H. Liang, Angew. Chem. Int. Ed. 2019, 58, 2580-2605.

[9] For recent labeling method using [11C]COCl2, see : a) C. Asakawa, M. Ogawa, M. Fujinaga, K. Kumata, L. Xie, T. Yamasaki, J. Yui, T. Fukumura, M. R. Zhang, Bioorg. Med. Chem. Lett. 2012, 22, 35943597; b) K. Kumata, J. Yui, Y. Zhang, Y. Kurihara, M. Ogawa, W. Mori, M. Fujinaga, M. R. Zhang, Bioorg. Med. Chem. Lett. 2017, 27, 4521-4524; c) T. Yamasaki, M. Fujinaga, Y. Shimoda, W. Mori, Y. Zhang, H. Wakizaka, M. Ogawa, M. R. Zhang, M.-R. Bioorg. Med. Chem. Lett. 2017, 27, 4114-4117.

[10] For a recent highlight on labeled phosgene-free carbonyl insertion, see : J.-P. J. Bow, P. J. Riss, Chemistry Methods, doi.org/10.1002/cmtd.202000029.

[11] For recent labeling method using [11C]CO see : a) T. Kihlberg, K. Farhad Karimi, B. Långström, J. Org. Chem. 2002, 67, 3687-3692; b) H. Doi, J. Barletta, M. Suzuki, R. Noyori, Y. Watanabe, B. Långström, B. Org. Biomol. Chem. 2004, 2, 3063-3066; c) S. Kealey, S. M. Husbands, I. Bennacef, A. D. Gee, J. Passchier, J. Label. Compd. Radiopharm. 2014, 57, 202-208; d) D. U. Nielsen, K.T. Neumann, A.T. Lindhardt, T. Skrydstrup, J. Label. Compd. Radiopharm. 2018, 61, 949-987.

[12] For a recent review on 11C-carbonylation chemistry, see : J. Eriksson, G. Antoni, B. Långström, O. Itsenko, Nucl. Med. Biol. https://doi.org/10.1016/j.nucmedbio.2020.02.005.

[13] [14C]CO is was reported to undergo spontaneous radiolysis. See: E. Hargraves, A. Lashford, A. Rees, B. Roughley, J. Label. Compd. Radiopharm. 2007, 50, 435-436.

[14] The use of $\mathrm{CO} 2$ to access non-isotopically labeled ureas is known. The gas reagent is used in undetermined excess and thus this would poorly suitable for radiolabeling. For examples, see: a) $Y$. Zhao, X. Guo, Z. Si, Y. Hu, Y. Sun, Y. Liu, Z. Ji, J. You, J. Org. Chem. 2020, 85, 13347-13353; b) M. Xu, A. Jupp, M. Ong, K. Burton, S. Chitnis, D. Stephan, Angew. Chem. Int. Ed. 2019, 58, $5707-5711$ and references cited therein; c) Y. Ren, S. Rousseaux, J. Org. Chem. 2018, 83, 913-920; d) S. Peterson, S. Stucka, C. Dinsmore, Org. Lett. 2010, 12, 1340-1343.

[15] a) A. Schirbel, M. Holschbach, H. Coenen, J. Label. Compd. Radiopharm. 1999, 42, 537-551; b) A. A. Wilson, A. Garcia, S. Houle, O. Sadovski, N. Vasdev, Chem. Eur. J. 2011, 17, 259-264; c) A. K. Haji Dheere, N. Yusuf, A. Gee, Chem. Commun. 2013, 49, 8193-8195; d) K. Horkka, K. Dahl, J. Bergare, C. S. Elmore, C. Halldin, M. Schou, ChemistrySelect 2019, 4, 1846-1849; e) K. Dahl, T. L. Collier, R. Cheng, X. Zhang, O. Sadovski, S. H. Liang, N. Vasdev, J. Label. Compd Radiopharm. 2018, 61, 252-262; f) J. Downey, S. Bongarzone, S. Hader, A. D. Gee, J. Label. Compd Radiopharm. 2018, 61, 263-271.

[16] E. W. van Tilburg, A.D. Windhorst, M. van der Mey, J. D. M. Herscheid, J. Label. Compd. Radiopharm. 2006, 49, 321-330.

[17] A. J. Poot, B. van der Wildt, M. Stigter-van Walsum, M. Rongen, R. C. Schuit, N. H. Hendrikse, J. Eriksson, G. A. M. S. van Dongen, A. D. Windhorst, Nucl. Med. Biol. 2013, 40, 488-497.

[18] For a recent example of sulfonylurea labeling with [11C]CO2, see : J. R. Hill, X. Shao, N. L. Massey, J. Stauff, P. S. Sherman, A. A. B. Robertson, P. J. H. Scott, Bioorg. Med. Chem. Lett. 2020, 30, 127186. 
[19] a) A. Del Vecchio, F. Caillé, A. Chevalier, O. Loreau, K. Horkka, H. Halldin, M. Schou, N. Camus, P. Kessler, B. Kuhnast, F. Taran, D. Audisio, Angew. Chem. Int. Ed. 2018, 57, 9744-9748; b) A. Del Vecchio, A. Talbot, F. Caillé, A. Chevalier, A. Sallustrau, O. Loreau, G. Destro, F. Taran, D. Audisio, Chem. Comm. 2020, 56, 11677-11680.

[20] For other methologies describing the synthesis of ureas from $\mathrm{CO}$, see : a) M. J. Fuchter, C. J. Smith, M. W. S. Tsang, A. Boyer, S. Saubern, J. H. Ryan, A. B. Holmes, Chem. Commun. 2008, 2152-2154 ; b) M. Marchegiani, M. Nodari, F. Tansini, C. Massera, R. Mancuso, B. Gabriele, M. Costa, N. Della Ca', J. CO2 Util. 2017, 21, 553-561; c) A. Ion, V. Parvulescu, P. Jacobs, D. D. Vos, Green Chem. 2007, 9, $158-$ 161; d) M. Tamura, K. Ito, Y. Nakagawa, K. Tomishige, J. Catal. 2016, 343, 75-85; e) F. Shi, Y. Deng, T. SiMa, J. Peng, Y. Gu, B. Qiao, Angew. Chem. Int. Ed. 2003, 42, 3257-3260.

[21] a) K. D. Collins, F. Glorius, Nat. Chem. 2013, 5, 597-601; b) K. D. Collins, A. Rühling, F. Glorius, Nat. Protoc 2014, 9, 1348-1353; c) K. D. Collins, A. Rühling, F. Lied, F. Glorius, Chem. Eur. J. 2014, 20, 3800-3805; d) T. Gensch, M. Teders, F. Glorius, J. Org. Chem. 2017, 82, 9154-9159; e) F. Schäfers, L. Quach, J. L. Schwarz, M. Saladrigas, C. G. Daniliuc, F. Glorius, ACS Catal. 2020, 10, 11841-11847.

[22] a) S. Friis, M. Johansson, L. Ackermann, Nat. Chem. 2020, 12, 511-519; b) H. Kim, G. Gerosa, J. Aronow, P. Kasaplar, J. Ouyang, J. Lingnau, P. Guerry, C. Fares, B. List, Nat. Comm. 2019, 10, 770; c) S. Lin, S. Dikler, W. D. Blincoe, R. D. Ferguson, R. P. Sheridan, Z. Peng, D. V. Conway, K. Zawatzky, H. Wang, T. Cernak, I. W. Davies, D. A. DiRocco, H. Sheng, C. J. Welch, S. D. Dreher, Science 2018, 361, eaar6236.

[23] N. J. Taylor, E. Emer, S. Preshlock, M. Schedler, M. Tredwell, S. Verhoog, J. Mercier, C. Genicot, V. Gouverneur, J. Am. Chem. Soc. 2017, 139, 8267-8276.

[24] The screening of additives was implemented in limited manner for carbon-11, see: H. Lee, P. Milner, M. Placzek, S. Buchwald, J. Hooker, J. Am. Chem. Soc. 2015, 137, 648-651.

[25] a) E. Vitaku, D. T. Smith, J. T. Njardarson, J. Med. Chem. 2014, 57, 10257-10274; b) M. D. Delost, D. T. Smith, B. J. Anderson, J. T. Njardarson, J. Med. Chem. 2018, 61, 10996-11020; c) K. A. Scott, J. T. Njardarson, Top. Curr. Chem. 2018, 376, 1.

[26] B. A. Salah. A. T. Kandil, M. G. Abd El Nasser, Res. Rev. J. Chem. 2018, 7, 38-48.

[27] a) G. Verardo, C. D. Venneri, G. Esposito, P. Strazzolini, P. Eur. J. Org. Chem. 2011, 2011, 13761384; b) A. Yagodkin, K. Löschcke, J. Weisell, A. Azhayev, Tetrahedron 2010, 66, 2210-2221.

[28] a) A. Motani, Z. Wang, M. Conn, K. Siegler, Y. Zhang, Q. Liu, S. Johnstone, H. Xu, S. Thibault, Y. Wang, P. Fan, R. Connors, H. Le, G. Xu, N. Walker, B. Shan, P. Coward, J. Biol. Chem. 2009, 284:76737680; b) C. Cioffi, N.Dobri, E. Freeman, M. Conlon, P. Chen, D. Stafford, D. Schwarz, K. Golden, L. Zhu, D. Kitchen, K. Barnes, B. Racz, Q. Qin, E. Michelotti, C. Cywin, W. Martin, P. Pearson, G. Johnson, K. Petrukhin, J. Med. Chem. 2014, 57, 7731-7757.

[29] I. Perkovic, M. Antunovic, I. Marijanovic, K. Pavic, K. Ester, M. Kralj, J. Vlainic, I. Kosalec, D. Schols, D. Hadjipavlou-Litina, E. Pontiki, B. Zorc, Eur. J. Med. Chem. 2016, 124, 622-636.

[30] J. Keith, R. Apodaca, M. Tichenor, W. Xiao, W. Jones, J. Pierce, M. Seierstad, J. Palmer, M. Webb, M. Karbarz, B. Scott, S. Wilson, L. Luo, M. Wennerholm, L. Chang, S. Brown, M. Rizzolio, R. Rynberg, S. Chaplan, J. Breitenbucher, ACS Med. Chem. Lett. 2012, 3, 823-827.

[31] M. Altman, C. Fischer, J. D. Katz, T. M. Williams, X. F. Zhang, H. Zhou, WO 2013/181075 Al.

[32] G. Martelli, M. Baiula, A. Caligiana, P. Galletti, L. Gentilucci, R. Artali, S. Spampinato, D. Giacomini, J. Med. Chem. 2019, 62, 10156-10166. 
[33] A. Pirzer, R. Lasch, H. Friedrich, H. Hubner, P. Gmeiner, M. Heinrich, J. Med. Chem. 2019, 62, 9658-9679.

[34] C. Asakawa, M. Ogawa, K. Kumata, M. Fujinaga, K. Kato, T. Yamasaki, J. Yui, K. Kawamura, A. Hatori, T. Fukulura, M.-R. Zhang, Bioorg. Med. Chem. Lett. 2011, 21, 2220-2223.

[35] a) B. H. Rotstein, S. H. Liang, J. P. Holland, T. L. Collier, J. M. Hooker, A. A. Wilson, N. Vasdev, Chem. Commun. 2013, 49, 5621-5629; b) B. H. Rotstein, S. H. Liang, M. S. Placzek, J. M. Hooker, A. D. Gee, F. Dollé, A. A. Wilson, N. Vasdev, Chem. Soc. Rev. 2016, 45, 4708-4726; c) X. Deng, J. Rong, L. Wang, N. Vasdev, L. Zhang, L. Josephson, S. H. Liang, Angew. Chem. Int. Ed. 2019, 58, 2580-2605; Angew. Chem. 2019, 131, 2604-2631; d) C. Taddei, V. W. Pike, EJNMMI Radiopharmacy and Chemistry 2019, 4, 25; e) P. J. H. Scott, Angewandte Chemie International Edition 2009, 48, 6001-6004. 